University for Business and Technology in Kosovo

UBT Knowledge Center

UBT International Conference

2015 UBT International Conference

Nov 7th, 9:00 AM - 5:00 PM

\title{
Implementation of E-education in Africa via Space Networks
}

Dimov Stojce llcev

Durban University of Technology, ilcev@dut.ac.za

Follow this and additional works at: https://knowledgecenter.ubt-uni.net/conference

Part of the Computer Sciences Commons, and the Digital Communications and Networking Commons

Recommended Citation

Ilcev, Dimov Stojce, "Implementation of E-education in Africa via Space Networks" (2015). UBT

International Conference. 87.

https://knowledgecenter.ubt-uni.net/conference/2015/all-events/87

This Event is brought to you for free and open access by the Publication and Journals at UBT Knowledge Center. It has been accepted for inclusion in UBT International Conference by an authorized administrator of UBT Knowledge Center. For more information, please contact knowledge.center@ubt-uni.net. 


\title{
Implementation of E-education in Africa via Space Networks
}

\author{
Dimov Stojce Ilcev \\ Durban University of Technology (DUT), Durban, RSA, \\ ilcev@dut.ac.za
}

\begin{abstract}
In this paper is introduced an advanced E-education provision in remote dispersed communities, such as rural, remote, mobile, agriculture, mining, construction, surveying, military, tourism and so on, based on the specific needs and requirements, implies significant broadband connectivity requirements, timely and quality-assured content delivery of service, applications and interactivity. The E-education solutions of distance learning and training for remote and rural areas, which are out of range of terrestrial and short distance wireless telecommunications facilities, cannot provide the broadband access without space-enabled communication infrastructures, such as satellite constellations and Stratospheric Platform Systems (SPS) or High Altitude Platforms (HAP). The paper also discusses the integration challenges that are presented by combining use of the space solutions for implementation Education and learning in urban, rural and mobile environments. The configuration of in-house design and development of Space Segment, installation of the scale-down Digital Video Broadcasting-Return Channel via Satellite (DVB-RCS) Hub as a Gateway, Ground Network and Interactive VSAT, known as Fixed Interactive Terminals (FIT), for E-education, distance learning and staff training initiative in Africa are described.
\end{abstract}

Keywords: DVB-RCS, DVB-S/S2, VDVoIP, Space and Ground Segment, Hub

\section{Introduction}

In the past are designed many proposals employing ICT and software support to provide E-education in remote environments, but these solutions couldn't work at all without implementing two-way space connectivity via Geostationary Earth Orbit (GEO), Medium Earth Orbit (MEO), Low Earth Orbit (LEO), SPS or Unmanned Aerial Vehicles (UAV), illustrated in Figure 1. Usually the best satellite solutions for E-education are GEO constellations deploying DVB-RCS standards and SPS with new proposed Digital Video Broadcasting-Return Channel via Platforms (DVB-RCP) technique and technologies. In addition, it will be necessary to examine a set of services and infrastructures that will realize E-education and distance learning systems for rural schools and corporate organizations and to assess the targeted users' interest in such specific applications. 


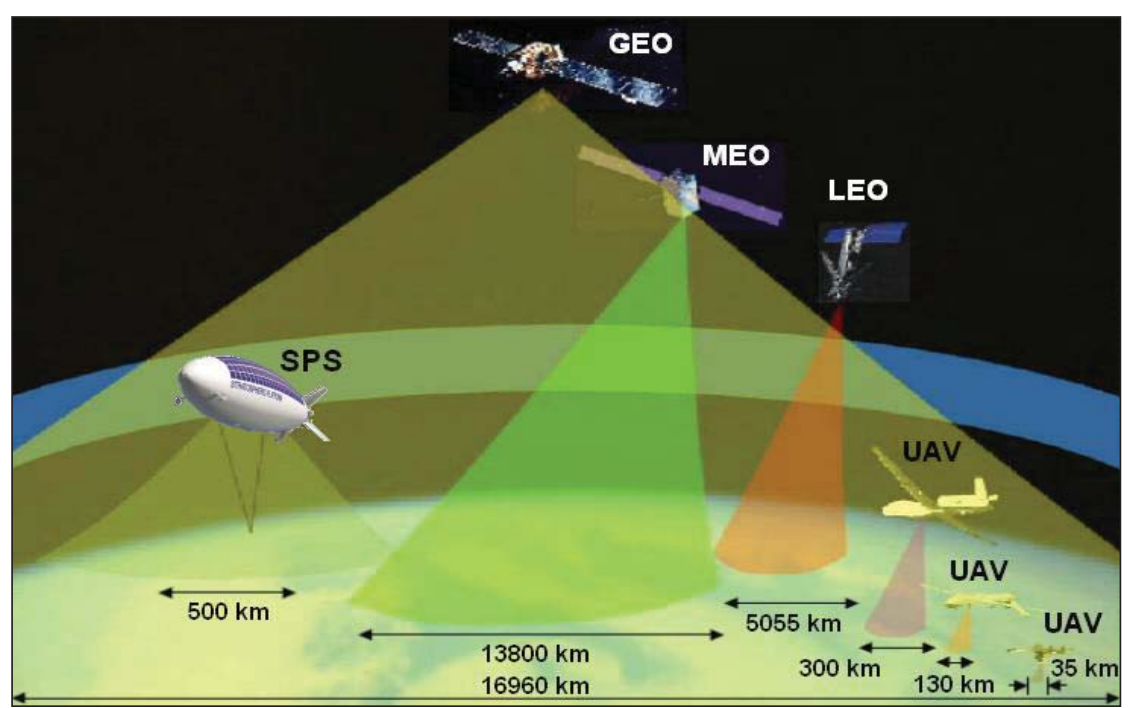

Fig. 1. Space Constellations in Function of E-education - Courtesy of Manual: by Ilcev [2]

The growing demand for satellite or platform communications bandwidth over all wireless media has motivated the introduction of digital solutions that provide bi-directional services at greater than 300 $\mathrm{MB} / \mathrm{s}$ known as DVB-RCS or RCP. Current DVB applications may demand rapid E-education installations at fixed locations of urban, suburban and rural environments, as well as mobile platforms, such as buses or vehicles for E-learning.

In such as way, more than a basic introduction, the DVB project presents the specific approaches to design and select an appropriate broadband satellite constellation deploying $\mathrm{C}, \mathrm{Ku}$ and Ka-bands. Then, it needs to configure ground elements, evaluate sources of antennas technology, Radio Frequency (RF) electronics equipment, services and solutions. This new technique can take into consideration all applications to commercial and government users as well as compliance with International Radio Regulations of International Telecommunication Union (ITU) [1], [2], [3].

\section{Development of E-education via Stratospheric Platform Systems (SPS)}

The SPS technologies will provide implementation of DVB-RCP access via airship for fixed and remote broadband connecting urban, rural and mobile platforms anywhere and in anytime. In fact, the development of the DVB-RCP infrastructure for E-education will need design of special airship that will act as geostationary very low orbit satellite at about 20 to $50 \mathrm{~km}$ in stratosphere, which network is shown in Figure 2. The SPS network contains space and ground segment and one airship can cover up to $500 \mathrm{~km}$ in radius. 


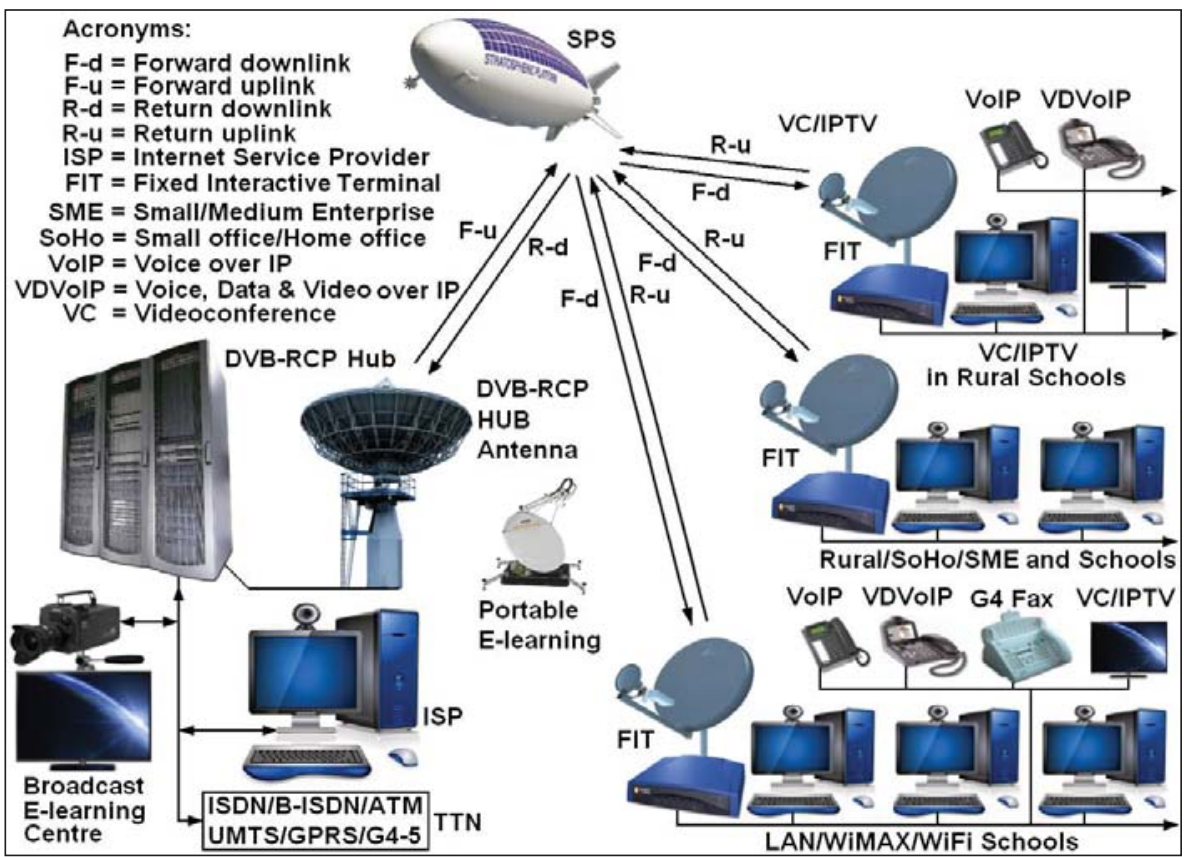

Fig. 2. E-education Solution via SPS Airship - Courtesy of Manual: by Ilcev [2]

Space segment includes one or several airship platforms connected via Inter Platform Links (IPL) using laser or optical links. Thus, deploying few airships with overlapping coverage will be covered a large land masses over one country. The ground segment consists Hub (Gateway) station interfaced to the Terrestrial Telecommunication Network (TTN), Internet Service Providers (ISP), Integrated Service Digital Network (ISDN), Broadband ISDN (B-ISDN), Asynchronous Transfer Mode (ATM), Universal Mobile Telecommunications System (UMTS), General Packet Radio Services (GPRS), G4 or G5 Cellular Networks and Broadcast E-learning Centre (BEC). On another side are connected users segment of rural schools to the BEC site via one or few airship platforms. Thus, educators in BEC can provide lessons of many subjects in the real time via Videoconference (VC) to the rural classrooms equipped with DVB Fixed Interactive Terminal (FIT) or Very Small Aperture Terminals (VSAT). On the roof of rural school or mast will be fixed DVB antenna as an Outdoor Unit (ODU) and inside of school will be installed DVB router or Indoor Unit (IDU). Router is able to connect up to 100 PC terminals in Local Area Network (LAN) by the cable lines or via Worldwide Interoperability for Microwave Access (WiMAX) and Wireless Fidelity (Wi-Fi) by the wireless links. The video lessons coming from BEC in rural schools have to be viewed via PC or common big $\mathrm{VC}$ screen and educator for each subject will be able to send soft copies of books and other learning materials. Pupils in rural schools can watch IPTV (IP Television) as well. 


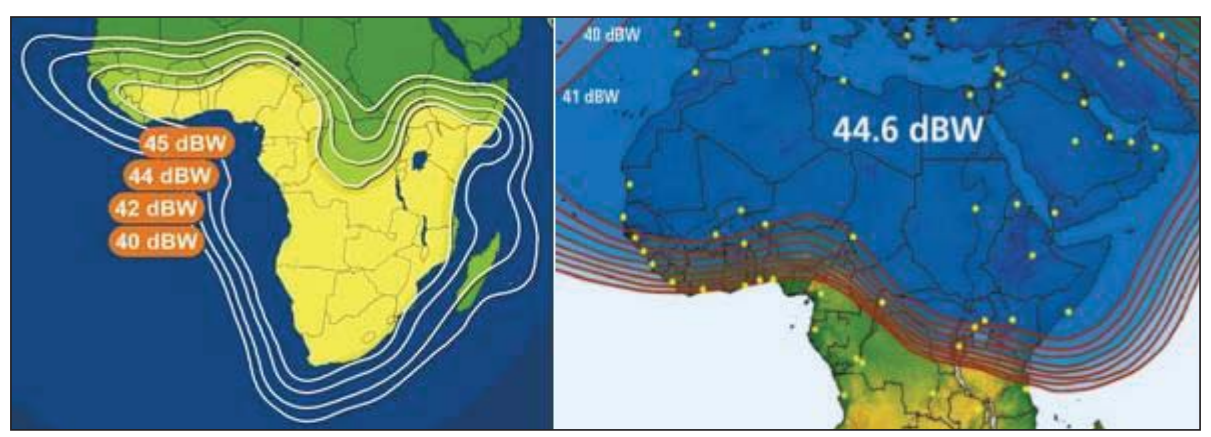

Fig. 3. DVB Space Segment Coverages - Courtesy of Brochures: by Eutelsat/Arabsat [4]

However, the schools offices, rural households, Small offices/Home offices (SoHo), Small/Medium Enterprises (SME), rural Internet kiosks and other sites will be connected to Internet, VC, IPTV, VoIP telephones, VDVoIP units and G4Fax machines. Managers of schools may be in touch in any time with their supervisors in Education Department and educators in BEC. Thus, as alternative can be used Portable E-learning VSAT.

From the geometrical point of view, the SPS airship terminals would enable very reliable rural communications that take much advantage of the best features of both terrestrial and satellite multipurpose communications. In addition, the system could bring advantages of its own, not available in current systems. The most important advantages of employing SPS are high elevation angles, broad coverage, low propagation delay, extremely low-cost operation, easy and incremental deployment and ability to move around the area in emergency situation.

The SPS airship can be launched using a specified volume of helium gas separated from the air to maintain its shape. As the platform rises the helium expands and at the proper altitude displaces all of the air within the airship. Once it is in the stratosphere the airship is remotely controlled and moved into determined position. The launch of SPS into position is much simpler than putting a satellite into any orbit. After careful preparation in the hangers, the airship is launched in 4 Ascent phases through the troposphere and Interface location point in the stratosphere and finally, it shifts to the stationkeeping position. The recovery phase goes in the opposite direction, namely, the airship is slowly moved from the station-keeping position towards the Interface point and from there descends down to the ground in 4 descent phases.

The SPS airships do not interfere aircrafts flights, because they are located over $10 \mathrm{Km}$, airship itself leverages new Lighter-Than-Air (LTA) technology being made of very high strength and lightweight materials. Airship is unmanned and solar powered platform, accompanied by advanced propulsion systems that maintain proper positioning, and it is also equipped with autonomous navigation, radio controlled command and communications payload stabilization systems. A combination of solar cells, batteries and fuel cells will power the SPS during its five-year planned deployment. 


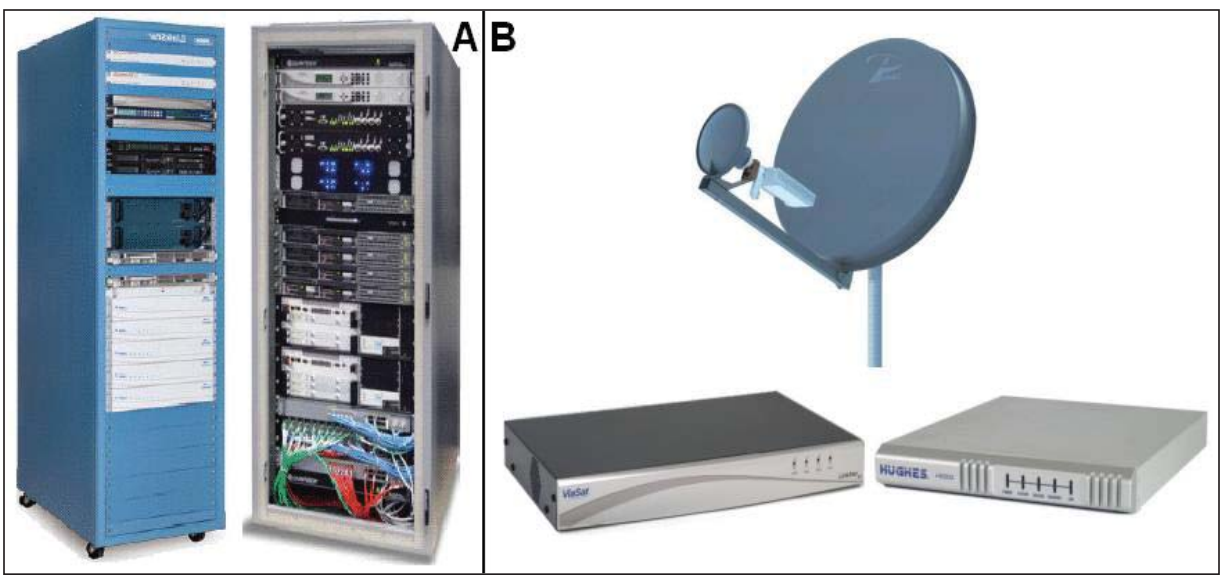

Fig. 4. DVB-RCS Ground Segment - Courtesy of Brochures by ViaSat/Cobham/Hughes [6]

Thus, SPS also incorporates telemetry to remotely transmit data (TT\&C) and redundant systems to serve as back-up measures, then features specific concept to provide the platform with very high level of availability, reliability and safety. The SPS is being designed to hold approximately $1,000 \mathrm{~kg}$ of communications payload capable of supplying fixed and mobile broadband, narrowband and wireless backbone services to approximately 3 million subscribers.

Immature SPS airships, their stabilization system and onboard antenna technology are challenging to be investigated, to avoid some inherent limitations belongs to the traditional systems and to provide backbone to cellular networks. Those are in the sense of a huge number of base stations required by the terrestrial system, limitation of the minimum cell size on the ground involved in GEO satellite system, and suffer from handover problem faced by LEO/MEO satellite system. With these great advantages, the ITU has allocated the spectrum to this system at $2 \mathrm{GHz}$ for $3 \mathrm{G}$ mobile systems, 48/47 $\mathrm{GHz}$ for the usage worldwide, and $31 / 28 \mathrm{GHz}$ band is allocated for usage in many countries [1], [2], [3], [4], [5].

\section{Development of E-education via Satellites}

The first generation of satellite standard of DVB-S known as an DVB-RCS, about 15 years ago, quickly became around the globe one of the key solution in almost every new advanced satellite communication projects for broadcast, broadband and multimedia interactive applications including high-speed Internet, IPPC and IPTV. The second generation of DVB-S2 CCM (Constant Coding Modulation) standard few years ago was presented as a new more cost effective, efficient, reliable, secure and functional solution. The DVB-S2 CCM is recently upgraded by the most technical and cost effective mode of DVB-S2 ACM (Adaptive Coded Modulation) standard as a forward and reverse compatible. 


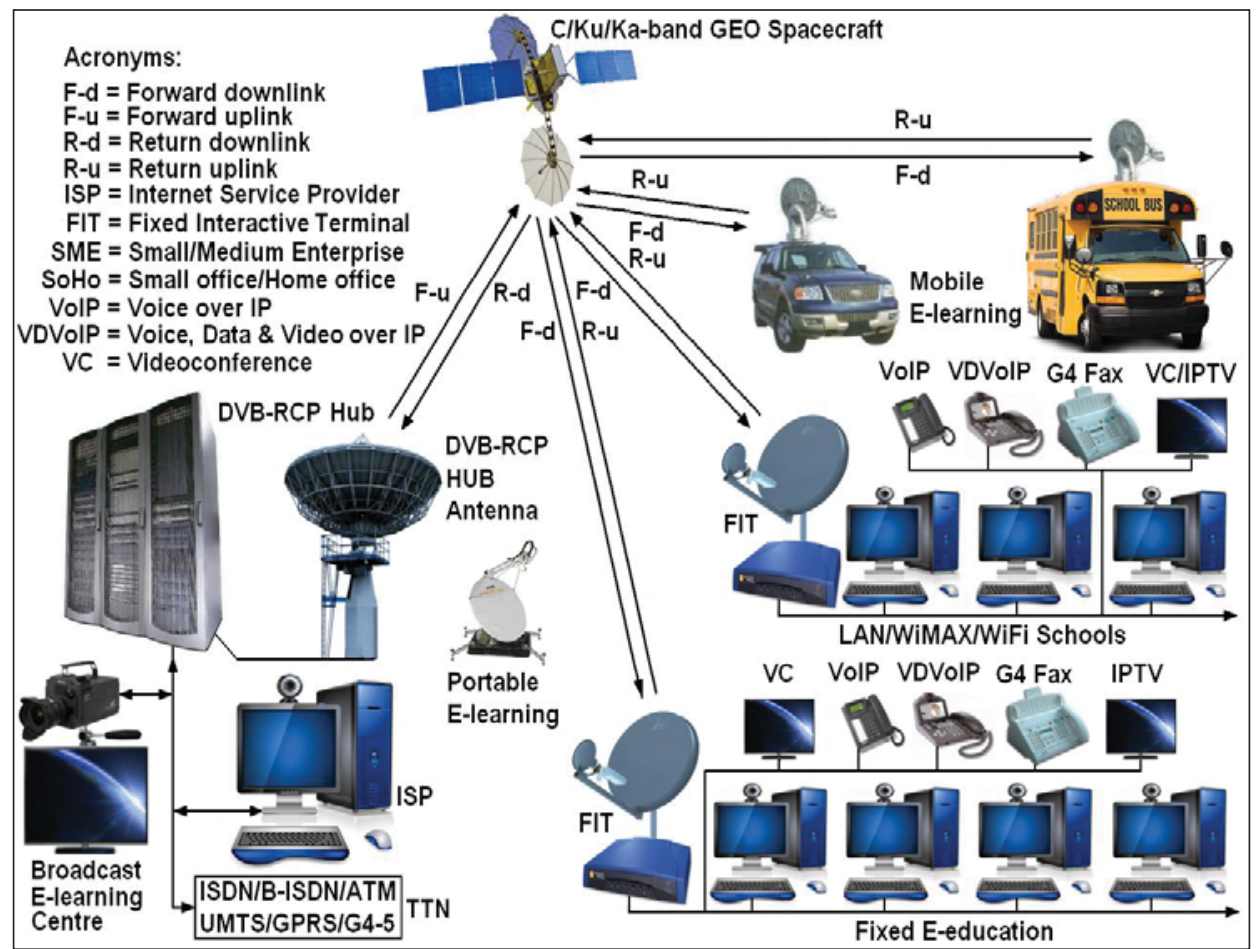

Fig. 5. E-education Solution via GEO Spacecraft - Courtesy of Book: by Ilcev [5]

The new DVB-S3 Third Generation of DVB-S Standard was proposed by the Israeli company NovelSat as more efficient successor to the DVB-S2 transmission system. After launching its new DVB-S3 (NS3) modulation technology in April 2011, as more efficient than DVB-S2, start-up NovelSat Company has already established 32 live satellite trials. The system firstly was deployed in a series of VSAT terminals and targeted as a replacement technology for DVB-S2 delivering VDV, Internet and IPTV from the sky to consumer homes and mobiles in remote areas.

For establishment DVB-RCS network in Northern and Southern Africa can be employed existing satellite operators providing the $\mathrm{C}, \mathrm{Ku}$ and $\mathrm{Ka}$-band Satellite Constellations suitable for DVB-RCS $\mathrm{S}$ and S2 scenario, which beam coverages are illustrated in Figure 3 (Left) of Eutelsat and in (Right) of Arabsat. There are many other DVB satellite operators such as Intelsat, SES-NewSkies, PanAmSat, Telesat, Inmarsat and others providing regional or global and spot beam coverage via GEO satellites. Presently in Africa are operational for regional coverage two satellites only: the Egyptian multipurpose spacecraft Nilesat and Nigerian NigComSat.

The British company Inmarsat awarded a contract to the US Boeing in August 2010 to design, build and supply three Inmarsat-5 satellites as part of an $752 \mathrm{M} £(1.2 \mathrm{~B} \$)$ wireless broadband network known as Global Xpress. 


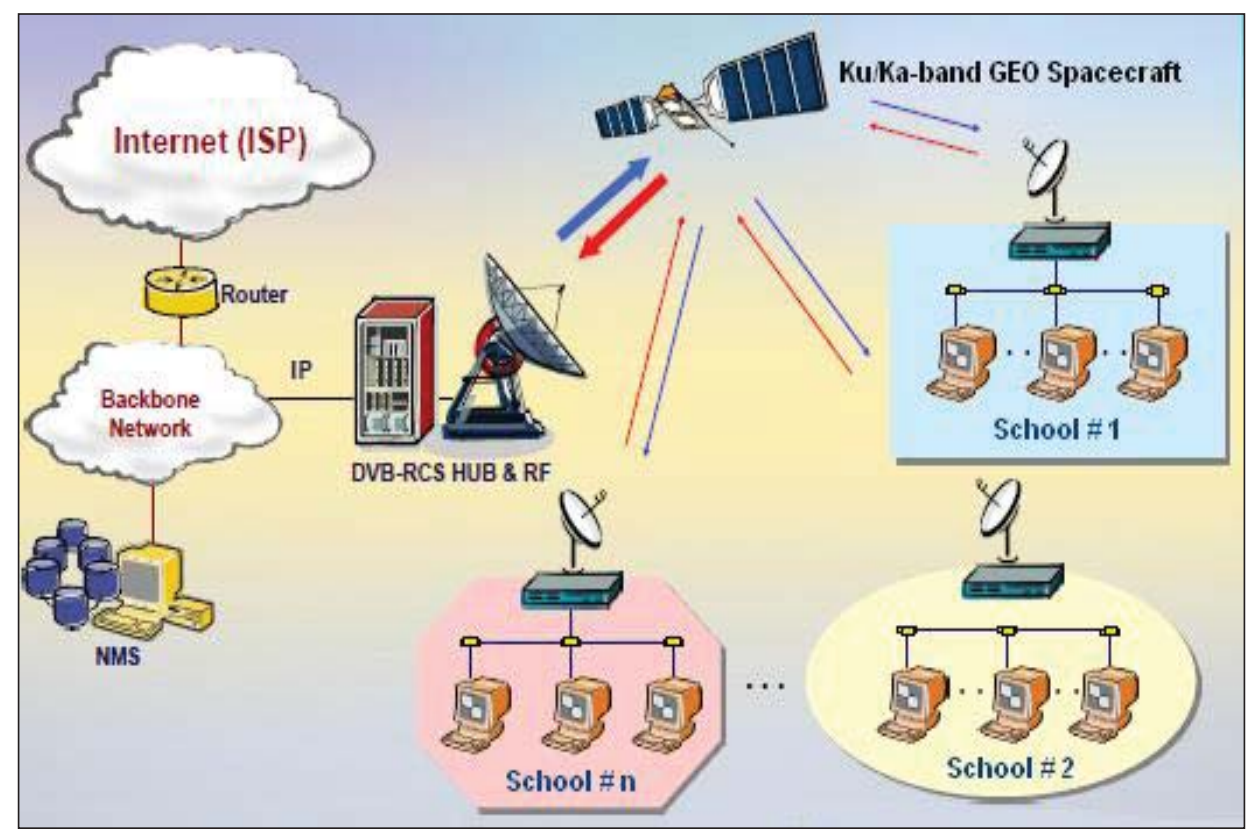

Fig. 6. E-education in Rural Schools via DVB-RCS Solution - Courtesy of Brochure: by NanoTronix [7]

This network will operate at Ka-band frequencies ranging between $18 \mathrm{GHz}$ and $31 \mathrm{GHz}$, which however possess more signal quality issues, compared to that of old $\mathrm{Ku}$-band (12GHz-18GHz) frequency range. Africa and Middle East have 69 countries, so dividing 1.2B \$ with 69 will be participation of about $17 \mathrm{M} \$$ per each country in the region to build 3 and $5.5 \mathrm{M} \$$ for 1 multipurpose GEO spacecraft.

The DVB-RCS Hubs are turnkey cost effective systems that can be installed in days to enable a wide range of government, corporate and private public network topologies with satellite interactive terminals including rural and learning applications, which two versions are shown in Figure 4A: ViaSat (Left) and Hughes (Right). Depending of type, but the biggest Hub terminals are able to support up to 80,000 VSAT or router terminals in urban, rural and remote environments, which two versions are shown in Figure 4B: ViaSat (Left) and Hughes (Right), and in Figure 4B (Above) is shown Cobham Patriot DVB-RCS antenna.

Thus, the DVB-RCS VSAT network has been designed to minimize the cost of scaling a broadcast, broadband, Internet and multimedia access between Hub terminals and hundred or thousands simultaneously logged-on FIT units in rural or remote areas providing E-education via GEO Satellite, shown in Figure 5. This E-education solution has almost the same as SPS infrastructure and solutions shown in Figure 2. In addition, the DVB-RCS VSAT network is providing Mobile E-learning solutions in special terrain vehicles and in school buses.

Each E-education vehicle integrates complete VSAT indoor (IDU) routers and on top of vehicle are installed VSAT outdoor (ODU) reflector antennas at C (4-8 GHz), Ku (12-18 GHz) or Ka-band (27$40 \mathrm{GHz}$ ). The VSAT equipment is connecting several PC configurations in LAN inside vehicles or via cables inside schools for interactive videoconference with Broadcast E-learning Centre (BES) in urban area. Educator is providing live lecture of remote education of any subject for each rural school, portable or mobile E-learning solution.

In Figure 6 is shown block diagram of typical rural E-education solution that connects urban and rural areas via DVB-RCS Hub, Radio Frequency (RS) antenna and $\mathrm{C} / \mathrm{Ku} / \mathrm{Ka}$-band GEO Spacecraft. On the urban side is ISP connected to Router, Backbone Network controlled by the Network 
Management System (NMS) and via Internet Protocol (IP) is linking Hub. The rural area contains the number of remote schools, which are equipped with VSAT routers, antenna and many PC terminals in LAN, WiMAX or WiFi networks. In every school pupils are watching live lecture at their PC monitors or videoconference screens. At the end of live lecture for each subject classroom teacher is asking pupils for any misunderstandings and is transferring transfer all questions to the educator in BEC studio for interactive discussion [2], [5], [7], [8].

\section{Conclusion}

The new DVB-S2 is designed to minimize overall system costs for service providers and system operators. Thus, this network offers the lowest costs on the market today for multiple access systems managing VoIP, VDVoIP, IPPC and IPTV multimedia, broadcast and broadband contents. The Eeducation solution throughout DVB-RCS will improve education and learning facilities in rural and urban areas and will help for better knowledge, information system and service delivery. These solutions via DVB-RCS will also help all schools, pupils and teacher to be better managed, controlled, inspected and educated countrywide. In all events, the implementation of DVB-RCS architecture will improve communication and Internet facilities in rural and remote environments for government and private corporation including emergency, disaster, security, education, health solutions and additional E-solutions.

\section{References}

1. Maral G., "VSAT Networks", John Wiley, Chichester, 2003.

2. Ilcev D. S. "Global Mobile CNS", DUT, Durban, 2011.

3. Zavala A.A. \& Others, "High-Altitude Platforms for Wireless Communications", Wiley, 2008.

4. WebPages: "GEO Satellite Operators: Eutelsat and Arabsat, 2008.

5. Ilcev D. S. "Global Aeronautical Communications, Navigation and Surveillance (CNS)", AIAA, Reston, 2013.

6. Web, "ViaSat [www.viasat.com], Cobham [www.cobham.com, Hughes [www.hughes.com]".

7. NanoTronix, "Two-way VSAT for E-learning", Seoul, 2011 [www.nano-tronix.com].

8. Ilcev D. S., "Stratospheric Communication Platforms (SCP) as an Alternative for Space Program", AEAT Journal, Emerald, Bingley, 2011. 